Investigating the Time Response of an Optical pH Sensor Based on a PolysiloxanePolyethylene Glycol Composite Material Impregnated with a pH-Responsive Triangulenium Dye

Frankaer, Christian G.; Sorensen, Thomas J.

Published in:

ACS Omega

DOI:

10.1021/acsomega.9b00795

Publication date:

2019

Document version

Publisher's PDF, also known as Version of record

Document license:

CC BY-NC

Citation for published version (APA):

Frankaer, C. G., \& Sorensen, T. J. (2019). Investigating the Time Response of an Optical pH Sensor Based on a Polysiloxane-Polyethylene Glycol Composite Material Impregnated with a pH-Responsive Triangulenium Dye. ACS Omega, 4(5), 8381-8389. https://doi.org/10.1021/acsomega.9b00795 


\title{
Investigating the Time Response of an Optical pH Sensor Based on a Polysiloxane-Polyethylene Glycol Composite Material Impregnated with a pH-Responsive Triangulenium Dye
}

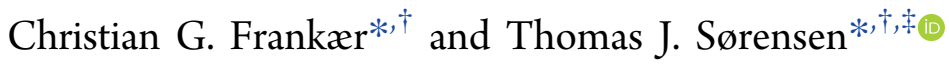 \\ ${ }^{\dagger}$ Nano-Science Center \& Department of Chemistry, University of Copenhagen, Universitetsparken 5, 2100 Copenhagen, Denmark \\ ${ }^{\ddagger}$ FRS-systems ApS, Hovedgaden 20, 4621 Gadstrup, Denmark
}

Supporting Information

\begin{abstract}
Determining the time it takes a sensor to report a change in the concentration of its target analyte may appear to be an easy task, but it is not. The dynamic characteristic of a sensor is determined by all components in the sensor system and the hydrodynamics of the sample. Here, the dynamic properties of an optical $\mathrm{pH}$ sensor were determined using the IUPAC-recommended activity step method in experimental setups that can determine sensorlimited response times longer than $5 \mathrm{~s}$. In order to do so, experimental setups for the injection and for the dipping method of determining the sensor time response were developed, tested, and shown to be able to determine time-

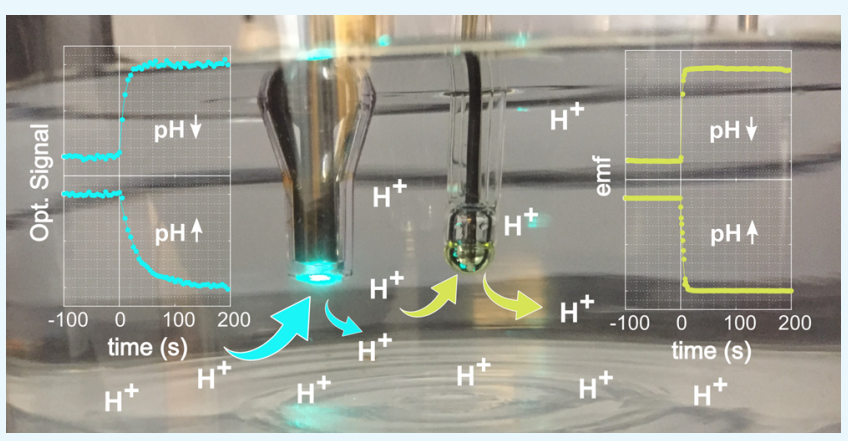
response curves with $1 \mathrm{~s}$ time resolution. This time resolution is shown to be sufficient for determining dynamic characterization of this optical $\mathrm{pH}$ sensor. The sensor chemistry-limited time-response curves were analyzed using curve fitting. It was found that the optode response time is limited by diffusion of protons within the sensor material when the proton concentration is reduced and limited by diffusion from the bulk to the boundary layer at the optode surface when proton concentration is increased. The latter is dependent on the magnitude of the change in analyte concentration and cannot be reported as a single response time. The investigation of the time response of the optical $\mathrm{pH}$ sensor reveals detailed information of the sensor chemistry, but does not yield a single response time of the sensor capable of describing the dynamic sensor characteristics of the optical $\mathrm{pH}$ sensor system.
\end{abstract}

\section{INTRODUCTION}

Development of $\mathrm{pH}$ sensors started in the beginning of the 20th century when the Danish chemist Sørensen defined $\mathrm{pH}$. He further described two methods to determine $\mathrm{pH}$ : the electrometric and the colorimetric. ${ }^{1}$ Based on the discovery of the membrane properties of glass, an electrode sensitive to protons was developed. ${ }^{2-4} \mathrm{~A}$ commercial $\mathrm{pH}$ meter was launched after 25 years of engineering. ${ }^{5}$ The colorimetric $\mathrm{pH}$ determination is based on indicator dyes, and the most successful commercialization is indicators immobilized on paper. ${ }^{6,7}$ Development of fiber optics, photo diodes, and lightemitting diodes (LEDs) has provided the means for a second implementation of the colorimetric method. ${ }^{8}$ During the last 40 years, optical $\mathrm{pH}$ sensors have been developed, ${ }^{9,10}$ yet only few are commercialized. ${ }^{11}$ The challenges for optical sensors are that they require a robust sensor dye that does not photobleach and an inert matrix material in which the sensor dye is robustly immobilized yet still has fast diffusion of protons in and out of the material. ${ }^{12-15}$ We have recently reported a new optical $\mathrm{pH}$ sensor, ${ }^{16,17}$ but as the technology is still emerging, characterization of $\mathrm{pH}$ measurements based on the colorimetric method is difficult. This is in stark contrast to
$\mathrm{pH}$ measurements based on the electrometric method for which standards have been established by the International Union of Pure and Applied Chemistry (IUPAC). ${ }^{18-20}$

When developing new sensors, the dynamic characteristics must be the first to be determined. This is the natural order, as the dynamic characteristics are fundamental to all static characteristics. $^{21-23}$ The most important dynamic characteristic is the response of the sensor to an input change, often given as the response time. While standard procedures exist for electrodes, ${ }^{19,24,25}$ analogue methods for optodes seem to be nonexistent. We recently discussed the dynamic characterization of optical sensors. ${ }^{23}$ Here, we benchmark the response of a $\mathrm{pH}$ optode against a commercial $\mathrm{pH}$ electrode. ${ }^{17,23} \mathrm{We}$ recently described our optimized sensor chemistry for determining $\mathrm{pH},{ }^{17}$ with $\mathrm{pH}$ responsive diazaoxa-triangulenium (DAOTA) dye covalently linked in an ORMOSIL matrix. ${ }^{16,17,26-28}$ The change in the fluorescence intensity of the responsive DAOTA emitter is converted into an optical sensor

Received: March 22, 2019

Accepted: April 30, 2019

Published: May 10, 2019 
signal with reference to the emission from a nonresponsive dye.

Addressing and reading the sensor chemistry is done using custom-built hardware that reports both the sensor signal and full emission spectra. ${ }^{17}$ Here, only the sensor signal is used to investigate the time-response of an optical $\mathrm{pH}$ sensor.

The response of chemical sensors can be limited by all parts of the sensor system, see Figure 1A..$^{16,17,23,29-31}$ If all hardware
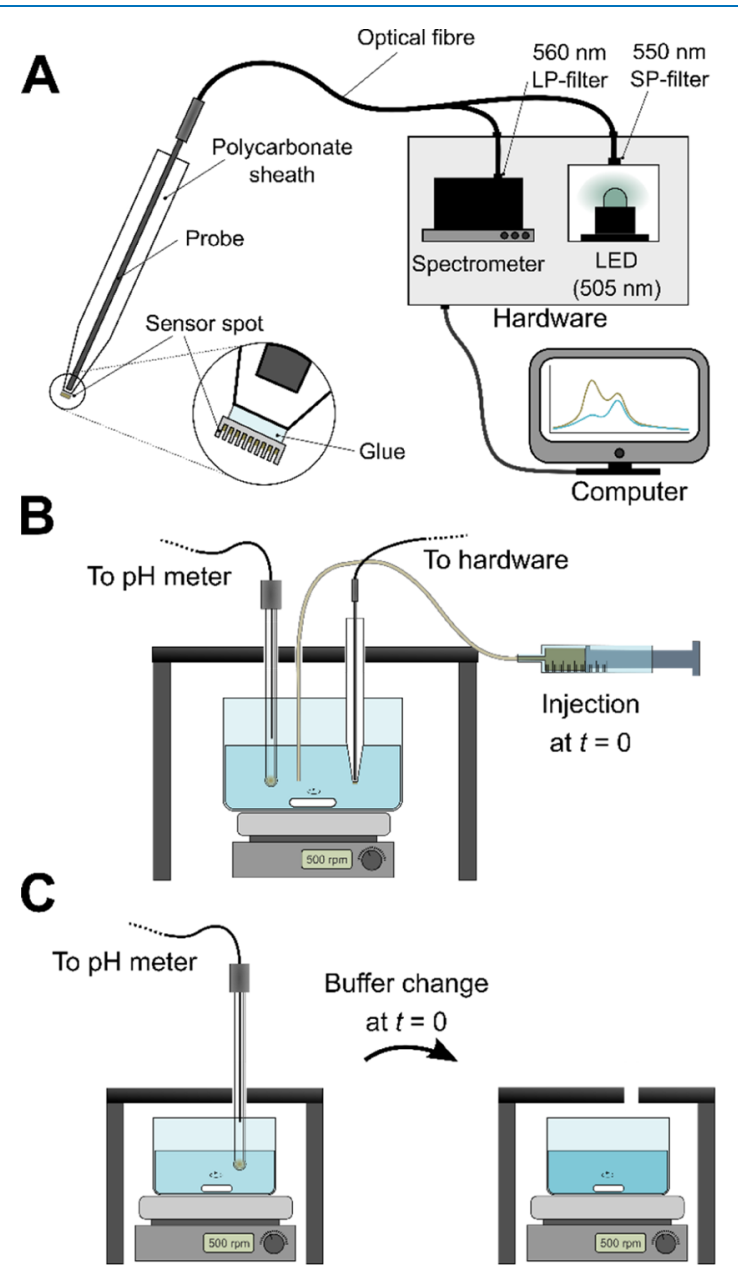

Figure 1. A) Outline of the sensor setup consisting of an optical sensor spot (optode) immobilized in front of an optical probe, fibre optical connectors, hardware encasing a fibre-spectrometer detector, and an LED light source. (B,C) Experimental setup for recording time-response data using the activity step method. (B) The injection method where electrode and optode responses can be recorded simultaneously. (C) The dipping method (here shown with an electrode).

components are fast, the response is determined by the sensor chemistry or by the mass transport of the target analyte in the sensor chemistry. Minimizing the influence of mass transport requires development of an experimental method that enables a change in the target analyte activity at the sensor that is as instantaneous as physically possible, or at least significantly faster than the sensor response itself. To probe the hydrodynamic parameters of the setup, time-response curves recorded with fast-responding commercial $\mathrm{pH}$ electrodes were used. With a setup with a fast analyte change and a hardware that enables rapid sampling, the contribution of the sensor chemistry to the time-response can be investigated. ${ }^{19}$
Figure 1 shows the two methods developed for investigating the sensor response. ${ }^{19,24,32,33}$ The injection method, shown in Figure $1 \mathrm{~B}$, alters the composition of a single solution, ${ }^{32}$ while the dipping method, shown in Figure 1C, takes the sensor from one solution to a second. ${ }^{33}$ In either method, the sensor responds to an induced activity step change. ${ }^{19,23}$ Here, both methods are used to compare the response properties of an optical $\mathrm{pH}$ sensor with those of commercial $\mathrm{pH}$ electrodes. Using a single magnitude of the activity step, the limiting hydrodynamic conditions were determined. Using the ideal hydrodynamic conditions, the sensor chemistry-limited time response was determined with a resolution of $1 \mathrm{~s}$ and setup defined response time determination limits of $5 \mathrm{~s}$ (dipping method) and $20 \mathrm{~s}$ (injection method).

By investigating the influence of the magnitude of the activity step on the time-response of the optical sensor, the limiting transport processes were identified. For $\mathrm{pH}$ electrodes, the previously reported response mechanism was confirmed that is response limited by diffusion from the bulk solution to the electrode surface through a stagnant film. ${ }^{23}$ The data showed that the response of the $\mathrm{pH}$ optode is limited by two different forms of transport depending on the direction of the activity step. For increasing $\mathrm{pH}$, diffusion within the matrix material is the response limiting process. While for decreasing $\mathrm{pH}$, diffusion from the bulk solution to the optode surface is the limiting process. The results demonstrate the need for a systematic approach when determining response times of chemosensors and clearly indicate which parameters can be optimized when engineering a faster sensor response.

\section{RESULTS AND DISCUSSION}

Determination of dynamic sensor properties requires careful design of the experimental method. The workflow used to optimize the experimental setup was recently discussed in great detail. $^{23}$ Robust determination of time-response curves is a prerequisite for investigating dynamic sensor characteristics determined by the sensor chemistry. ${ }^{19,34}$ In the following, the experimental parameters are investigated to ensure that the response-limiting component of the chemosensors is the sensor chemistry.

Response Curve Analysis. For optical chemosensors, the first important parameter to consider is the activity step used to determine the time-response curve. ${ }^{23}$ The $\mathrm{pH}$ optode has an operational range of $3 \mathrm{pH}$ units centered at its characteristic $\mathrm{p} K_{\mathrm{a}}$-value of the responsive dye which in this case is 6.1. For setup development, an activity step of $2 \mathrm{pH}$ units (i.e. a 100fold change in $\left[\mathrm{H}^{+}\right]$) centered at the $\mathrm{p} K_{\mathrm{a}}$-value was chosen. This corresponds to the $\mathrm{pH}$ change between 5.1 and 7.1. All response curves were recorded in a 2-(N-morpholino)ethanesulfonic acid (MES) buffer system, which has a $\mathrm{p} K_{\mathrm{a}}$ value of 6.15 resulting in an optimal overlap between the buffer region of high buffer capacity and the operational range of the sensor.

Figure 2 shows representative normalized time-response curves for optodes and electrodes recorded for $\mathrm{pH}$ decrease or increase by $2 \mathrm{pH}$ units. The response curves contain error, $\sigma$, determined as $\sim 2.5 \%$ for optodes and $\sim 0.5 \%$ for electrodes. Thus, the response times for optodes and electrodes should be determined as $t_{\alpha}$ with $\alpha<97.5 \%$ and $\alpha<99.5 \%$, respectively. ${ }^{23}$ The optical signal output from the optode was determined as the fluorescence intensity ratio between the $\mathrm{pH}$ responsive dye and the reference dye, ${ }^{17}$ and the signal output from the electrodes is the open circuit potential. Time-response curves 

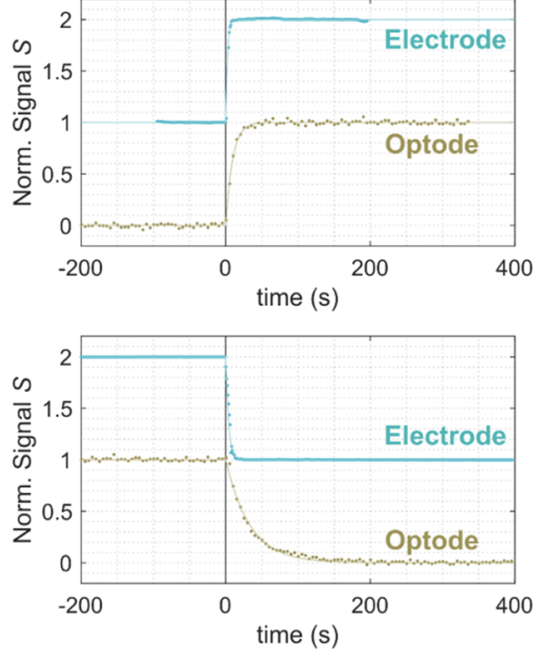

Figure 2. Selected normalized time-response curves for optodes (olive) and electrodes (blue) showing signal outputs, $S$, as a function of time. Top: $\mathrm{pH}$ decrease from 7.1 to 5.1. Bottom: $\mathrm{pH}$ increase from 5.1 to 7.1. (.) Experimental data (-) curve fit using eq 1.

are the signal output, $S$, plotted as a function of time, $t .^{19,23,35} \mathrm{~A}$ first order empirical model was used for curve fitting analysis of the time-response curves using the following equation ${ }^{23,36}$

$$
S(t)= \begin{cases}S_{0} & \text { for } t<0 \\ S_{\infty}-\left(S_{\infty}-S_{0}\right) \exp \left(-k\left(t-t_{\mathrm{d}}\right)\right) & \text { for } t \geq 0\end{cases}
$$

where $S$ is the sensor signal changing from $S_{0}$ to $S_{\infty}$, and subscripts 0 and $\infty$ denoting initial and final steady-state signal values. $t_{\mathrm{d}}$ is the delay time, which is defined as the length of time between introduction of the input change of the operator and the first significant effect of the input change seen in the output, thereby including both dead time and lag time, see ref 23. $k$ is the rate constant defined as $1 / \tau$, where $\tau$ is the time taken to obtain a signal conversion of $\sim 63 \%$.

For optodes, Figure 2 shows that $90 \%$ of the response $\left(t_{90}\right)$ has occurred after approx. 20 and $60 \mathrm{~s}$ for $\mathrm{pH}$ decrease and increase, respectively. Similar $t_{90}$-values for electrodes are $5 \mathrm{~s}$. As shown in Figure 2, response data were recorded long enough to ensure that the steady-state signal could be determined with high confidence. Each steady-state value was determined at $5 \times t_{90}$, which corresponds to a signal conversion $\alpha$ of $>99.99 \%$ using the model described by eq $1 .^{23}$

Prior to curve fitting analysis, all time-response curves were normalized against the steady-state signal output using the following procedure: The baseline was calculated by averaging the data points recorded before the activity step change and the steady-state signal was calculated by averaging all data points recorded after $3 \times t_{90}$. This corresponds to a signal

\section{Table 1. Response Characteristics of Optical pH Sensors}

\begin{tabular}{|c|c|c|c|}
\hline $\begin{array}{l}\text { manufacturer/ } \\
\text { reference }\end{array}$ & short description of $\mathrm{pH}$ sensor, and test procedure & & dantity \&; value \\
\hline Presens & $\mathrm{pH}$ optode. Well agitated solutions at $37^{\circ} \mathrm{C}$. No specifications on $\mathrm{pH}$ jump reported & $t_{90}$ & $<120 \mathrm{~s}$ \\
\hline Finesse & pH optode. Agitated solutions. Activity jump or temperature not reported & $t_{90}$ & $<60 \mathrm{~s}$ \\
\hline Polestar & $\mathrm{pH}$ optode. No description of method & $t_{90}$ & $<40 \mathrm{~s}$ \\
\hline Ocean Optics & Optode integrated in a cuvette. No description of method & $t_{90}$ & $\sim 10 \mathrm{~s}$ \\
\hline 37 & $\begin{array}{l}\text { absorption intensity of Congo Red immobilized in a TEOS matrix and deposited on a PMMA fibre. Response tested by } \\
\text { immersion of a probe into standard buffers ranging with a pH change from } 8 \text { to } 5 \text { (a), or pH change from } 5 \text { to } 8 \text { (b) }\end{array}$ & $t_{90}$ & $\begin{array}{l}\text { (a) } t_{90} \approx 2 \mathrm{~s},(\mathrm{~b}) \\
t_{90} \approx 4 \mathrm{~min}\end{array}$ \\
\hline 38 & $\begin{array}{l}\text { fluorescence lifetime of ruthenium complexes immobilized in hydrogels and deposited on polyester substrates. } \mathrm{pH} \text { change from } \\
6.5 \text { to } 9 \text { (a) and from } 9 \text { to } 6.5 \text { (b) }\end{array}$ & $t_{9}$ & $\begin{array}{l}\text { (a) } t_{90} \approx 7-10 \mathrm{~s} \\
\quad(\mathrm{~b}) \\
t_{90} \approx 10-25 \mathrm{~s}\end{array}$ \\
\hline 39 & $\begin{array}{l}\text { ratiometric fluorescence intensity of HPTS immobilized in a PDMS/APTES/TEOS matrix on an optical fibre. Response tested } \\
\text { by immersion of probe into } 100 \mathrm{mM} \text { Tris buffers. } \mathrm{pH} \text { change from } 2.5 \text { to } 8.3\end{array}$ & $t_{90}$ & $t_{90}=13 \mathrm{~s}$ \\
\hline 40 & $\begin{array}{l}\text { absorption intensity of phenol red in a TEOS/PhTES matrix and deposited on glass slides. Response tested by immersion of glass } \\
\text { slides in cuvettes. } \mathrm{pH} \text { change from } 5 \text { to } 10(\mathrm{a}) \text { and } \mathrm{pH} \text { change from } 5 \text { to various } \mathrm{pH} \text { in the range } 8 \text { to } 12(\mathrm{~b})\end{array}$ & $t_{95}$ & $\begin{array}{l}\text { (a) } t_{95} \approx 5-600 \mathrm{~s}^{a} \\
\text {,(b) } t_{95} \approx 30 \mathrm{~s}^{b}\end{array}$ \\
\hline 41 & $\begin{array}{l}\text { evanescent wave absorption of bromocresol purple and bromocresol green immobilized in TEOS on silica fibres. } \mathrm{pH} \text { change from } \\
4 \text { to } 11(\mathrm{a}) \text {, and from } 11 \text { to } 4 \text { (b) }\end{array}$ & $?$ & $\begin{array}{l}\text { (a) } \sim 5 \mathrm{~s},(\mathrm{~b}) \\
\sim 30 \mathrm{~s}\end{array}$ \\
\hline 42 & $\begin{array}{l}\text { absorption variation of swelled TEOS/TMOS without dyes deposited on a silica fibre. Absorption varies with } \mathrm{pH} \text {. } \mathrm{pH} \text { change } \\
\text { from } 2.0 \text { to } 10.4 \text { and back }\end{array}$ & $t_{90}$ & $t_{90} \approx 1-5 \mathrm{~min}$ \\
\hline 43 & $\begin{array}{l}\text { ratiometric fluorescence intensity of mercurochrome immobilized in a TMOS/MTMOS matrix. Optode was made by packing } \\
\text { fragmented sol-gel particles in a flow cell. Tested in the } \mathrm{pH} \text { range } 3 \text { to } 8\end{array}$ & $t_{90}$ & $t_{90} \approx 3-4 \mathrm{~min}$ \\
\hline 44 & $\begin{array}{l}\text { combined } \mathrm{pH} / \mathrm{DO} / \text { temperature sensor. The } \mathrm{pH} \text { sensor is based on fluorescence life time of HPTS immobilized in a PMMA/ } \\
\text { aminoethylacrylamide matrix on an optical fibre, Tested in buffers with a } \mathrm{pH} \text { change from } 9 \text { to } 4 \text { (a), and } 4 \text { to } 9 \text { (b) }\end{array}$ & $t_{95}$ & $\begin{array}{l}\text { (a) } t_{95} \approx 2 \mathrm{~min} \\
\text { (b) } t_{95} \approx 3 \mathrm{~min}\end{array}$ \\
\hline 45 & $\begin{array}{l}\text { ratiometric fluorescence intensity of chlorophenyliminopropenylaniline and the reference dye Macrolexfluorescence yellow } 10 \\
\text { GN immobilized in a PVC/bis(2-ethylhexyl)phthalate matrix on a polyethylene terephthalate substrate. pH change from } 7 \text { to } 9 \\
\text { and back }\end{array}$ & $t_{90}$ & $t_{90} \approx 60 \mathrm{~s}$ \\
\hline 46 & $\begin{array}{l}\text { fluorescence intensity of } \mathrm{Ru} \text { complexes immobilized in a TEOS/PhTES matrix on an optical fibre. Tested by immersion of the } \\
\text { probe into buffers in the } \mathrm{pH} \text { range of } 2.0-8.1\end{array}$ & $?$ & $30 \mathrm{~s}$ \\
\hline 47,48 & $\begin{array}{l}\text { ratiometric excitation intensity of HPTS immobilized in GPTMS/ETES on glass. Tested in a flow cell with a pH change from } 5 \\
\text { to } 7 \text { and back }\end{array}$ & $t_{90}$ & $t_{90}=12 \mathrm{~s}$ \\
\hline 49 & $\begin{array}{l}\text { absorption intensity of methyl red and bromocresol green immobilized in a TEOS/GPTMS matrix on glass slides. Response } \\
\text { tested by immersion in cuvettes with } 0.1 \mathrm{M} \mathrm{HCl} \text { then buffer with a } \mathrm{pH} \text { of } 8.06 \text { (a) and back (b) }\end{array}$ & $t_{95}$ & $\begin{array}{l}\text { (a) } t_{95} \approx 20 \mathrm{~s},(\mathrm{~b}) \\
t_{95} \approx 1 \mathrm{~s}\end{array}$ \\
\hline 50 & $\begin{array}{l}\text { fluorescence intensity of aminofluorescein immobilized in a TMOS/PhTES matrix, on glass slides. Response tested in } 20 \mathrm{mM} \\
\text { phosphate buffer with a } \mathrm{pH} \text { change from } 4.7 \text { to } 8.3 \text { (a) and } 8.3 \text { to } 4.7 \text { (b) }\end{array}$ & $t_{95}$ & $\begin{array}{l}\text { (a) } t_{95} \approx 90 \mathrm{~s},(\mathrm{~b}) \\
t_{95} \approx 120 \mathrm{~s}\end{array}$ \\
\hline 51 & $\begin{array}{l}\text { fluorescence intensity of fluorescein immobilized in a PVA/TMOS matrix on glass. Tested in a flow cell with a pH change from } 3 \\
\text { to } 9 \text { (a) and } 9 \text { to } 3 \text { (b) }\end{array}$ & $t_{95}$ & $\begin{array}{l}\text { (a) } t_{95} \approx 6 \mathrm{~min} \\
\quad(\mathrm{~b}) \\
t_{95} \approx 2.5 \mathrm{~min}\end{array}$ \\
\hline
\end{tabular}

${ }^{a}$ Depending on sol-gel composition. ${ }^{b}$ Faster from pH 5 to 12 , than from $\mathrm{pH} 5$ to 8 . 
conversion $\alpha$ of $\sim 99.9 \%$ using the model in eq 1 . That is, the steady-state signal was evaluated from data sampled beyond 99.9\% conversion. In this time interval, any change due to the activity step change will be within the error $\sigma$. Note that within the given level of $\sigma$, drift was not detected. ${ }^{23}$

The curve fitting analysis using eq 1 is suitable for determining the dynamic properties of the $\mathrm{pH}$ optode and the $\mathrm{pH}$ electrodes. All time-response curves and corresponding curve fits are included in the Supporting Information.

Influence of Experimental Conditions. Attention to experimental conditions is crucial if useful and reliable timeresponse curves are to be obtained. Time-response curves from systematic data analysis may reveal the properties of the sensor chemistry. Table 1 highlights this by compiling time-response information from commercial $\mathrm{pH}$ optodes and from optical $\mathrm{pH}$ sensors reported in the literature. As the experimental conditions in all cases are different-and in most cases only partially described-comparing the reported information is difficult. We may tentatively conclude that the $\mathrm{pH}$ optode investigated here has a response time similar to or lower than that of other optical sensors based on fluorescence. However, to compare the performance of the sensor chemistries, more attention must be given to the experimental conditions.

The conditions described in the experimental section are those used for determining the activity step dependence, and these have been carefully optimized. However, both of the IUPAC recommended methods have their limitations: the response time determined by the injection method is limited by the homogenization time and hydrodynamic conditions, which may influence the first part of the time-response curve. ${ }^{23}$ But because the position of the electrode/optode remains unchanged, the method is excellent for determining whether a response is instantaneous. When using the dipping method, the data points collected during the period where the electrode/ optode is moved between samples interrupt the continuity of the time-response curve, and rejection of these data may be required. Hence, judging whether a response is instantaneous relies on how fast the switch between reservoirs can be performed. Here, this time was $2-3$ s. To illustrate possible pitfalls, examples on how the hydrodynamic conditions influence the time-response curves must be discussed.

Figure 3 shows time-response curves from $\mathrm{pH}$ optodes and $\mathrm{pH}$ electrodes following a $\mathrm{pH}$ decrease from 7.1 to 5.1 using the injection method. The curves in the center and bottom panel of Figure 3 were recorded at a very slow agitation speed (50 rpm). When injection of acid is carried out far from the optode (i.e. the bottom of the reservoir), delay times of 30-40 s were observed, see Figure 3 bottom panel. When acid is injected in vicinity of the optode/electrode (i.e. in the same depth as the optode/electrode tip), fluctuations in the sample solution result in a signal overshoot, see Figure 3 central panel. Such curves are not suitable for response time analysis and should be avoided. The conclusion is that injection far from the optode/electrode and close to the agitator provides acceptable homogenization of the sample solution before the effect of the activity change is sensed, thereby ensuring monotonous time-response curves suitable for determination of response times.

High speed agitation, however, may also result in inadequate time-response curves, as seen in the top panel of Figure 3. Agitation at $900 \mathrm{rpm}$ generates bubbles that lead to unstable hydrodynamic conditions. The effect is most prominent for the optode, where bubbles build up on the surface of the optode
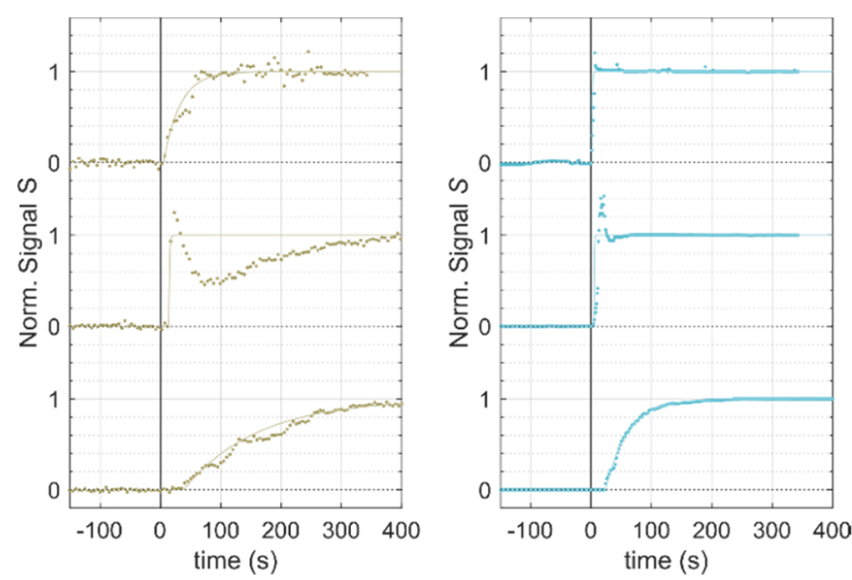

Figure 3. Normalized time-response curves for optodes (left; olive) and electrodes (right; blue) recorded under different hydrodynamic conditions for $\mathrm{pH}$ decrease from 7.1 to 5.1. Bottom: delay time observed when using the injection method with a very low agitation speed (50 rpm), and injection far from the electrode/optode. Center: overshoot when using the injection method with a very low agitation speed $(50 \mathrm{rpm})$ and injection in the proximity of the electrode/ optode. Top: increased error when using a high agitation speed (900 $\mathrm{rpm}$ ) which induces bubbles that disturb the measurement.

disturbing the measurement, but the effect was also observed in the response of the $\mathrm{pH}$ electrode, where an increased $\sigma$ is observed (see the Supporting Information).

Another important parameter to consider when using the injection method is the injection speed relative to the time resolution of the experiment. Figure 4 shows two time-

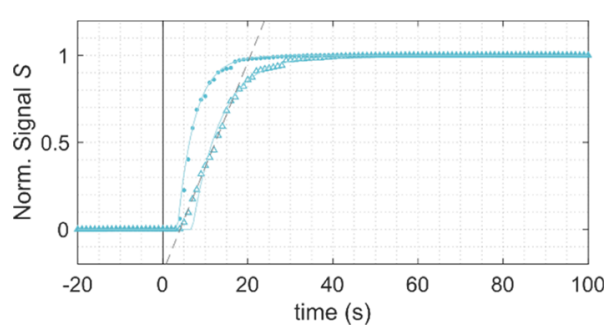

Figure 4. Normalized time-response curves for a glass electrode recorded at a high agitation speed $(600 \mathrm{rpm})$ with a time resolution of $1 \mathrm{~s}$. Injection was performed at two different rates: $20(\boldsymbol{\Delta})$ and 100 $\mathrm{mL} / \mathrm{min}(\mathbf{O})$. A linear tangent was fitted to the first part of the timeresponse curve recorded with $20 \mathrm{~mL} / \mathrm{min}$ as a guide for the eye.

response curves for a glass $\mathrm{pH}$ electrode recorded at a high agitation speed $(600 \mathrm{rpm})$ providing fast homogenization and thereby a fast sensor chemistry-limited response. The hardware has a time resolution of $1 \mathrm{~s}$, and injection was performed at two different rates: 20 and $100 \mathrm{~mL} / \mathrm{min}$. Using a volume of $4 \mathrm{~mL} 1$ $\mathrm{M} \mathrm{HCl}$, the injections are completed within 12 and $2.4 \mathrm{~s}$, respectively. Figure 4 shows that a response is observed for both rates of injection after a delay time of approx. $5 \mathrm{~s}$, but that the response is markedly slower for injection at $20 \mathrm{~mL} / \mathrm{min}$. The time-response is almost linear and is identical to the rate of injection. Careful analysis of the result reveals that the electrode response is fast in this case and the limiting factor is the rate of injection. As the object of study is the sensor and the sensor chemistry of the $\mathrm{pH}$ optode in particular, the rate of injection-introduced artefact is a problem, and we must conclude that in the injection method the injection must be completed within a time period shorter than the time 
resolution of the experiment ( $1 \mathrm{~s})$. Thus, the experimental setup must be optimized for agitation speed, positions of sensors and injection, and speed of injection if reliable timeresponse curves are to be determined with the injection method.

At agitation speeds $<400 \mathrm{rpm}$, it was observed that timeresponse curves recorded from electrodes were susceptible to overshoots, as seen in the central panel of Figure 3. Overshoots occurred even if the injection was carried out far from the tip of the electrode. The susceptibility towards an overshoot is a result of the fast electrode response, see Figure 2. Slower responding bulk sensors i.e., the $\mathrm{pH}$ optode studied here, are less susceptible to overshoots. Therefore, we investigated the effect of agitation on the time-response curves using different setups for the slower optodes and the fast electrodes.

For a slower optical $\mathrm{pH}$ sensor, the injection was carried out in vicinity of the $\mathrm{pH}$ optode, see the detailed setup in Supporting Information Figure S1, and time-response curves Figures S2-S4, S9-S11, and S14-S16. A series of timeresponse curves recorded at different agitation speeds for a $\mathrm{pH}$ decrease from 7.1 to 5.1 is shown in Figure 5a. Response times evaluated as $t_{90}$, are plotted as a function of agitation speed in Figure 5c.

For the fast sensors, fast injection $(100 \mathrm{~mL} / \mathrm{min})$ was carried out in vicinity of the agitator (see the detailed setup in Supporting Information Figure S1 and time-response curves in Figures S5, S6, S12, S13, S17, S18). A series of time-response curves recorded at different agitation speeds of a $\mathrm{pH}$ electrode
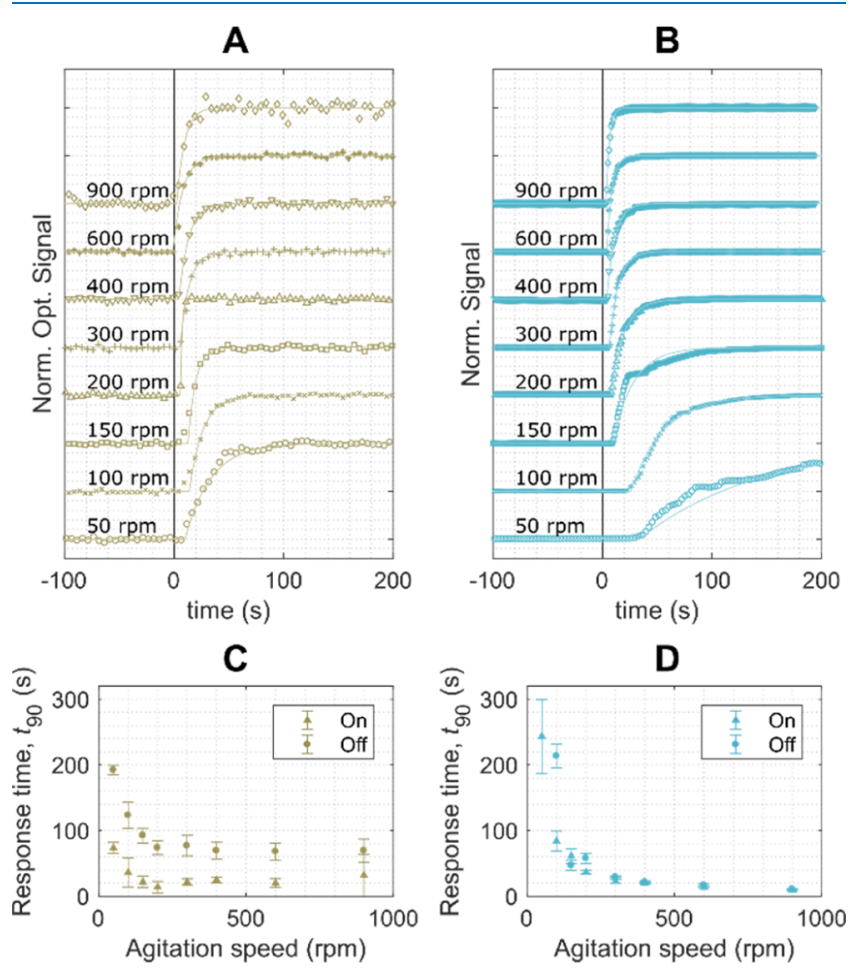

Figure 5. Correlation between response and agitation speed for the $\mathrm{pH}$ optode (left; olive) and the $\mathrm{pH}$ electrodes (right; blue). (A,B): normalized time-response curves recorded at different agitation speeds for a $\mathrm{pH}$ decrease from 7.1 to 5.1. Injection is performed in vicinity of the optode (A), but at the bottom of the reservoir for the electrode (B) to avoid an overshoot. (C,D): response time evaluated as $t_{90}$ plotted against the agitation speed for the $\mathrm{pH}$ decrease $(\mathrm{on} ; \boldsymbol{\Delta})$ and $\mathrm{pH}$ increase (off; $\mathrm{O}$ ). for a $\mathrm{pH}$ decrease from 7.1 to 5.1 are shown in Figure $5 \mathrm{~b}$. Response times evaluated as $t_{90}$ are plotted as a function of agitation speed, see Figure $5 \mathrm{~d}$.

In either case, an increase in the response time was observed when decreasing the agitation speed. For the fast electrochemical sensors, a time resolution of $1 \mathrm{~s}$ was used. Although the overshoot was avoided by injection close to the agitator, a significant delay time was observed, $\sim 40 \mathrm{~s}$ at $50 \mathrm{rpm}$. The delay time decreases with increasing agitation speeds and settles at $\sim 5 \mathrm{~s}$ for agitation speeds higher than $200 \mathrm{rpm}$. A slower colorimetric sensor was investigated with a time resolution of $5 \mathrm{~s}$. Here, the injection close to the agitator resulted in no significant delay time.

The critical setup parameters, agitation speed and the duration and position of the injection, are summarized in Table 2. Within the experimentally determined values, the dynamic sensor properties can be determined from the curve fitting. ${ }^{23}$ These are included in Table 2. Using the injection method to induce a $\mathrm{pH}$ decrease, both $\mathrm{pH}$ optodes and $\mathrm{pH}$ electrodes are characterized by a response time of $t_{90} \sim 20 \mathrm{~s}$. However, for a $\mathrm{pH}$ increase the optode response is slower, while the electrode response is unchanged. To rationalize this observation, we need to look at the influence of the magnitude of the activity step.

Elucidating Physical Processes Involved in the Response. With the optimized setup, the influence of the size of the activity step magnitude on the response of the sensors was investigated. The response times given as $t_{90}$ were determined by curve fitting analysis using eq 1 (see Figures S9-S18). Figure 6 shows the correlation between $t_{90}$ and the magnitude of the activity step for the two experimental methods. A comparison shows that $t_{90}$-values determined using the injection method are typically 10-20 s higher than those determined by the dipping method. This is a general trend for both optodes and electrodes, and it is particularly pronounced for high activity steps, where the injection volume is large. As the data analysis takes delay time into account, this indicates the presence of a setup induced time delay of $\sim 15 \mathrm{~s}$, originating from the mixing process that will be present in any geometry where $\mathrm{pH}$ is adjusted by adding acid or base to a stirred solution.

By analyzing the data in Figure 6, we concluded that the setup clearly limits the response time that can be ascribed to the sensor, and that this limiting behavior for each method is reflected directly by the fast responding electrodes. Thus, the sensor related response times that can be determined must be slower than $\sim 5 \mathrm{~s}$ for the dipping and $\sim 20 \mathrm{~s}$ for the injection method. Hence, we can conclude (i) that the activity change experienced by the sensor for each method is completed within 5 and $20 \mathrm{~s}$, respectively, and (ii) that the sensor chemistrylimited response time, $t_{90}$, is less than $5 \mathrm{~s}$ for the electrodes used in this study in both directions of the activity step.

Further characterization of the response of the glass electrodes will require a flow system, ${ }^{34}$ analogue to the methods described in references, ${ }^{52,53}$ and subsequently a higher data readout frequency (the $\mathrm{pH}$ meter used only allows one readout every second).

All response times determined for optodes, given as $t_{90}$, exceed $5 \mathrm{~s}$. Thus, all time-response curves recorded for optodes using the dipping method are limited by the sensor chemistry. With the injection method, optode response times exceeding $20 \mathrm{~s}$ are only observed for activity steps where $\log \left(a_{0} / a_{\infty}\right)>$ -1 , meaning that time-response curves recorded using this 
Table 2. Setup Requirements and Response Properties of the Optode and the Electrode Determined by the Injection Method

\begin{tabular}{|c|c|c|}
\hline & optode & electrode \\
\hline \multicolumn{3}{|c|}{ Setup } \\
\hline agitation speed (rpm) & $>300$ & $>300$ \\
\hline injection duration (s) & $<8$ & $<2.4^{a}$ \\
\hline Injection position & $1 \mathrm{~cm}$ below the surface & injection tube \\
\hline time resolution, $t_{\text {res }}(\mathrm{s})$ & 5 & 1 \\
\hline$t_{\max }(\mathrm{on} / \mathrm{off})(\mathrm{s})$ & $>300 />600$ & $>300 />300$ \\
\hline activity step, $a_{0} / a_{\infty}$ (on/off) & $100 / 0.01$ & $100 / 0.01$ \\
\hline \multicolumn{3}{|c|}{ Data } \\
\hline noise, $\sigma$ & $\sim 2.5 \%$ & $\sim 0.5 \%$ \\
\hline$\alpha_{\max }$ & $97.5 \%$ & $99.5 \%$ \\
\hline \multicolumn{3}{|c|}{ Curve Fit } \\
\hline model type & eq 1 & eq 1 \\
\hline$k(\text { on/off })^{b}$ & $0.14 \pm 0.04 / 0.034 \pm 0.006$ & $0.17 \pm 0.04 / 0.14 \pm 0.05$ \\
\hline$t_{90}^{b}$ & $22 \pm 5 / 71 \pm 12$ & $19 \pm 4 / 23 \pm 5$ \\
\hline$t_{95}^{b}$ & $27 \pm 6 / 93 \pm 15$ & $23 \pm 5 / 28 \pm 7$ \\
\hline$t_{99}^{b}$ & & $33 \pm 7 / 40 \pm 11$ \\
\hline delay time, $t_{\mathrm{d}}$ & $<7 \mathrm{~s}$ & $<6 \mathrm{~s}$ \\
\hline goodness of fit, $R^{2}$ & $>0.994$ & $>0.994$ \\
\hline
\end{tabular}

${ }^{a}$ Maximal injection rate possible with given equipment. ${ }^{b}$ Mean of fitted time-response curves from 3 optodes or 2 electrodes recorded at agitation speeds 300,400 , and $600 \mathrm{rpm}$.

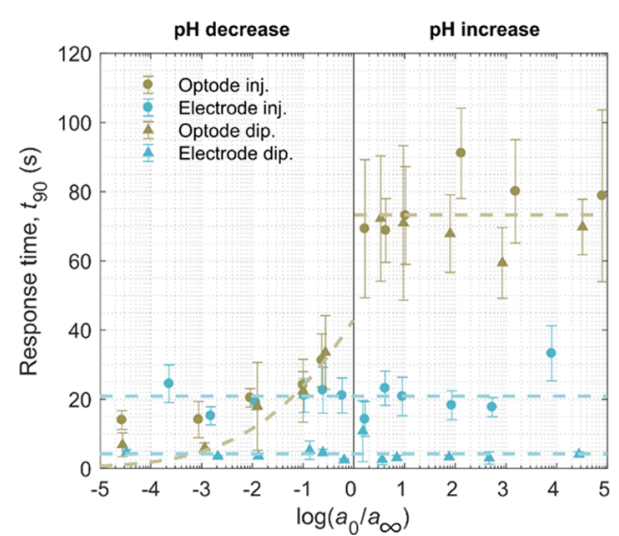

Figure 6. Response time $t_{90}$ for optodes (olive) and electrodes (blue) measured by the injection method $(\mathbf{0})$ and the dipping method $(\boldsymbol{\Delta})$, and plotted as a function of the magnitude of the activity step $a_{0} / a_{\infty}$.

method will contain method-induced contributions when $\log \left(a_{0} / a_{\infty}\right) \leq-1$, that is, in all experiments where $\mathrm{pH}$ is decreased.

For the optodes, the fastest response was observed when $\mathrm{pH}$ was decreased (proton activity increased). The response of increased $\mathrm{pH}$ was significantly slower (proton activity decreased). This suggests that two different processes, as outlined in Figure 7, control the response.

When the proton activity is increased $\left(\log \left(a_{0} / a_{\infty}\right)<0\right)$, the response time decreases with increasing activity step, indicating a diffusion controlled response. That is, diffusion of protons within the boundary layer covering the optode surface limits the time-response of the optode response. In this case, the driving force is the $\left[\mathrm{H}^{+}\right]$-gradient, which is controlled by the activity step size. It was found that the diffusion model described in ref 25 was able to describe all 36 time-response curves for activity steps with increased proton activity (three optodes, each six different activity steps, two methods, see Figures S19-S24) with a single response parameter, $k$

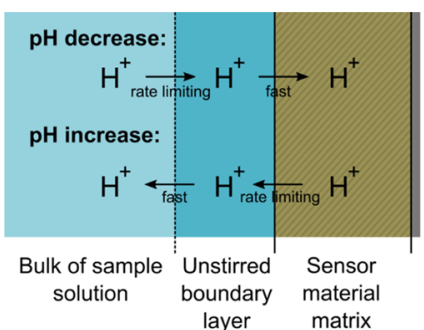

Figure 7. Diffusion routes of protons at the interface between the optode and the sample solution through an unstirred boundary layer. The rate-limiting processes are indicated.

$$
k=\frac{\pi^{2} D}{4 \delta^{2}}
$$

where $D$ is the mean diffusion coefficient and $\delta$ is the thickness of the boundary layer, see the Supporting Information for details. This value was determined, $k=0.06 \pm 0.01 \mathrm{~s}^{-1}$. The result is included in Figure 6 (olive dashed; left panel).

When the proton activity is decreased $\left(\log \left(a_{0} / a_{\infty}\right)>0\right)$, the response time was observed to be independent of the activity step size, and diffusion of protons within the organic phase of the optode is controlling the response speed. ${ }^{54}$ It was found that the diffusion model described in ref 54 was able to describe all 36 time-response curves for activity steps with decreased proton activity (three optodes, each six different activity steps, two methods, see Figures S19-S24) with a single response parameter, $k=0.027 \pm 0.006 \mathrm{~s}^{-1}$. The result is included in Figure 6 (olive dashed; right panel).

Having identified the response limiting processes directly informs how the response time can be minimized. For a rapid response when the $\mathrm{pH}$ increases, the thickness of the sensor material film must be reduced, while a rapid response when the $\mathrm{pH}$ decreases can be achieved by minimizing the boundary layer thickness. The latter can be achieved by minimizing the surface tension of the sensor matrix, for example, by surface functionalization. 


\section{CONCLUSIONS}

The dynamic sensor properties of an optical $\mathrm{pH}$ sensor were determined. By recording time-response curves under varying hydrodynamic conditions, an experimental setup was developed and experimental parameters were optimized to ensure that the sensor response is determined by the properties of the sensor chemistry. The experimental setup developed here is able to determine sensor limited response times higher than 20 $\mathrm{s}$ for the injection method and higher than $5 \mathrm{~s}$ for the dipping method to determine the time-response of chemosensors. This is sufficient to investigate the time-response of most optical sensors.

The dynamic characteristics of the optical $\mathrm{pH}$ sensor based on a polysiloxane-polyethylene glycol composite polymer with a $\mathrm{pH}$ responsive triangulenium dye reveal that the sensor has a response time of $t_{90}=71 \pm 12 \mathrm{~s}$ when the $\mathrm{pH}$ is increased, and that the response varies with the magnitude of the activity step when the $\mathrm{pH}$ is decreased (average $t_{90}=22 \pm 5 \mathrm{~s}$ ). The difference was rationalized using two models for the mass transport of protons. The models differ in the type of rate limiting mass transport: For the $\mathrm{pH}$ increase, the response time is limited by diffusion of protons within the sensor material. For a $\mathrm{pH}$ decrease, the response time is determined by the thickness of the boundary layer on the optode.

We conclude that the detailed studies as the ones described here are not only necessary if we are to compare sensor performance, but also reveal important properties of the sensor chemistry and provide the information needed for informed sensor optimization.

\section{MATERIALS AND METHODS}

MES monohydrate and MES sodium salt were purchased from Sigma-Aldrich in analytical grade $(>99.0 \%)$. Deionized water was used without further purification.

Preparation of Sample Solutions. All measurements were carried out in sample solutions containing 0.020 M MES buffer. Two stock solutions containing $0.020 \mathrm{M}$ MES were prepared from MES monohydrate (buffer A) and MES sodium salt (buffer B), respectively. $\mathrm{pH}$ values of the two solutions were 4.2 and 7.8. Sample solutions containing 0.020 M MES at different $\mathrm{pH}$ values ranging from $\mathrm{pH} 4.2$ to 7.8 were prepared by mixing buffer $\mathrm{A}$ and buffer $\mathrm{B}$ in different ratios. Sample solutions containing $0.020 \mathrm{M} \mathrm{MES}$ at $\mathrm{pH}$ values outside the 4.2-7.8 range were prepared from pure solutions of either buffer A or buffer B, respectively, titrated with $1 \mathrm{M} \mathrm{HCl}$ or $1 \mathrm{M}$ $\mathrm{NaOH}$.

Optical pH Sensor. The fabrication of sensor spots is described elsewhere. ${ }^{16,17}$ Each sensor spot was glued to the outside tip of an injection molded polycarbonate sheath using a transparent UV-curing glue (UV adhesive U305, Cyberbond Europe $\mathrm{GmbH}$ ), see Figure 1A. A home-built hardware setup was used in the experiments. ${ }^{17}$ A blue-green LED (505 nm, NSPE310S, Nichia) was used as the light source. The light was filtered using a $550 \mathrm{~nm}$ short-pass filter (Omega Optical) before it was coupled to a QR600-7-VIS125BX optical probe (Ocean Optics). The polycarbonate sheath was placed over the optical probe centering the tip of the probe $3 \mathrm{~mm}$ above the sensor spot. The fluorescence light emitted from the sensor spot was collected through the QR600-7-VIS125BX optical probe (Ocean Optics) and guided into the fiber spectrometer (FREEDOM vis-NIR, Ibsen Photonics) through a $560 \mathrm{~nm}$ long-pass filter (Omega Optical). An automated software routine allowed a readout of 12 fluorescence spectra per minute.

pH-Meters. Two pH-meters (Mettler-Toledo Seven Compact) were used to measure $\mathrm{pH}$. The $\mathrm{pH}$ meters were equipped with two different $\mathrm{pH}$ electrodes (a Mettler-Toledo, InLab Micro Pro and a Mettler-Toledo, InLab Expert Pro) both with a diameter of $5 \mathrm{~mm}$ and a surface area of $\sim 40 \mathrm{~mm}^{2}$. The $\mathrm{pH}$ electrodes were calibrated using a series of four standard technical buffer solutions at $\mathrm{pH} 2.00,4.01,7.00$, and 10.00 (NIST traceable, Mettler-Toledo, InLab solutions).

Recording Time-Response Curves Using the Injection Method. The experimental setup is shown in Figure 1B. A bar magnet (length $30 \mathrm{~mm}, 6 \mathrm{~mm} \varnothing$ ) was placed in a $450 \mathrm{~mL}$ crystallization bowl (115 $\mathrm{mm} \varnothing$, height $65 \mathrm{~mm}$ ), hereafter denoted as the reservoir. Then, $250 \mathrm{~mL}$ sample solution was transferred to the reservoir creating a liquid column with a height of $27 \mathrm{~mm}$. The reservoir was placed on a magnetic stirrer, and agitation at $500 \mathrm{rpm}$ was applied unless otherwise stated. A black table was placed above the reservoir to shield the sample solution from changes in ambient light. $\mathrm{pH}$ electrodes and optodes were immersed into the reservoir through the black table $40 \mathrm{~mm}$ from the vortex centre with an angle of $90^{\circ}$ with respect to the liquid surface and positioned with the tip $10 \mathrm{~mm}$ beneath the surface. The electrodes and optodes were allowed to pre-equilibrate for $10 \mathrm{~min}$.

Recording time-response curves of optodes: After preequilibration, data were recorded for at least $3 \mathrm{~min}$ before an aliquot of either $1 \mathrm{M} \mathrm{HCl}$ or $1 \mathrm{M} \mathrm{NaOH}$ was injected. A small volume of $\mathrm{HCl}$ or $\mathrm{NaOH}$ was injected from a $20 \mathrm{~mL}$ syringe equipped with Teflon tubing $(0.5 \mathrm{~mm} \varnothing), 40 \mathrm{~mm}$ from the vortex centre and $1 \mathrm{~cm}$ below the surface of the sample solution using a syringe pump (KDS, Legato 100) with a speed of $30 \mathrm{~mL} / \mathrm{min}$, see the Supporting Information for details. Maximum injection duration was $8 \mathrm{~s}$. The temperature was recorded simultaneously using the $\mathrm{pH}$ meters. The temperature was constant within $0.2{ }^{\circ} \mathrm{C}$ throughout each experiment. Optical signals were read out every $5 \mathrm{~s}\left(t_{\text {res }, \mathrm{O}}=5 \mathrm{~s}\right)$. The experiment was stopped after recording data for at least 5 times $t_{90}$.

Recording time-response curves of electrodes: After preequilibration, data were recorded for at least $1.5 \mathrm{~min}$ before an aliquot of either $1 \mathrm{M} \mathrm{HCl}$ or $1 \mathrm{M} \mathrm{NaOH}$ was injected from a $50 \mathrm{~mL}$ syringe equipped with Teflon tubing $(0.5 \mathrm{~mm} \varnothing) . \mathrm{HCl} /$ $\mathrm{NaOH}$ was injected through an inlet tube at the solution surface, see the Supporting Information for details. The inlet tube was positioned $20 \mathrm{~mm}$ from the vortex centre with an opening $(5 \mathrm{~mm} \varnothing)$ at the bottom of the reservoir. Injection was performed using a syringe pump (KDS, Legato 100) with a speed of $100 \mathrm{~mL} / \mathrm{min}$. Maximum injection duration was $2.4 \mathrm{~s}$. The temperature was recorded simultaneously with the electric potential on the $\mathrm{pH}$ meters. The temperature was constant within $0.2{ }^{\circ} \mathrm{C}$ throughout each experiment. Optical signals were read out every second $\left(t_{\text {res, } \mathrm{E}}=1 \mathrm{~s}\right)$. The experiment was stopped after recording data for at least 5 times $t_{90}$.

Recording the Response Using the Dipping Method. The experimental setup is shown in Figure 1C. Two sample solutions consisting of $0.02 \mathrm{M}$ MES buffer with different $\mathrm{pH}$ values corresponding to the activity step change were prepared: A bar magnet (length $20 \mathrm{~mm}, 6 \mathrm{~mm} \varnothing$ ) was placed in a crystallization bowl ( $95 \mathrm{~mm} \varnothing$, height $55 \mathrm{~mm}$ ), hereafter denoted the reservoir. Then, $200 \mathrm{~mL}$ sample solution was transferred to the reservoir creating a liquid column with a height of $30 \mathrm{~mm}$. Two reservoirs were placed on magnetic 
stirrers, and agitation at $500 \mathrm{rpm}$ was applied (IKA C-Mag HS7). A black table was placed above the reservoir to shield the sample solution from changes in ambient light that may interfere with the optical signals. $\mathrm{pH}$ electrodes and optodes (as described above) were immersed into the reservoir through the black table $20 \mathrm{~mm}$ from the vortex centre with an angle of $90^{\circ}$ with respect to the liquid surface and positioned with the tip $15 \mathrm{~mm}$ beneath the surface. The electrodes and optodes were allowed to pre-equilibrate for $10 \mathrm{~min}$ in the first buffer solution. Hereafter, data were recorded for at least $3 \mathrm{~min}$ before the sensors were rapidly removed from the first buffer solution and immediately immersed into the second buffer solution. This procedure did not take more than $3 \mathrm{~s}$. The temperature was recorded using the $\mathrm{pH}$ meters, and was constant within $0.1{ }^{\circ} \mathrm{C}$ throughout the experiment. Electric potentials were read out every second $\left(t_{\text {res }, E}=1 \mathrm{~s}\right)$ and optical signals were read out every $5 \mathrm{~s}\left(t_{\mathrm{res}, O}=5 \mathrm{~s}\right)$. The experiment was stopped after recording data for at least $5 \times t_{90}$.

\section{ASSOCIATED CONTENT}

\section{(S) Supporting Information}

The Supporting Information is available free of charge on the ACS Publications website at DOI: 10.1021/acsomega.9b00795.

Detailed experimental descriptions, all data recorded in the form of time-response curves, and fitted timeresponse data (PDF)

\section{AUTHOR INFORMATION}

\section{Corresponding Authors}

*E-mail: Christian@chem.ku.dk (C.G.F.).

*E-mail: TJS@chem.ku.dk (T.J.S.).

\section{ORCID $\odot$}

Thomas J. Sørensen: 0000-0003-1491-5116

\section{Notes}

The authors declare the following competing financial interest(s): TJS is a founder and current owners of FRSsystems ApS, a University of Copenhagen Spin-Out company commercializing the optical $\mathrm{pH}$ sensors investigated in this manuscript.

\section{ACKNOWLEDGMENTS}

The authors thank Villum Fonden (grant\#14922), BIOPRO, Innovationsfonden (grant\#5179-00914B), UpX, and the University of Copenhagen.

\section{ABBREVIATIONS}

APTES, (3-aminopropyl)triethoxysilane; DAOTA, diazaoxatriangulenium; DO, dissolved oxygen; ETES, ethyltriethoxysilane; GPTMS, (3-glycidyloxypropyl)trimethoxysilane; HPTS, 8-hydroxypyrene-1,3,6-trisulfonic acid; IUPAC, International Union of Pure and Applied Chemistry; LED, light emitting diode; MES, 2-( $N$-morpholino)ethanesulfonic acid; MTMOS, methyltrimethoxysilane; PDMS, polydimethylsiloxane; PET, polyethylene terephthalate; PMMA, poly(methyl methacrylate); PrTES, propyltriethoxysilane; PhTES, phenyltriethoxysilane; PS, polystyrene; TDI, terrylene diimide; TEOS, tetraethylorthosilicate; TMOS, tetramethylorthosilicate

\section{REFERENCES}

(1) Sørensen, S. P. L. Über die Messung und die Bedeutung der Wasserstoffionenkonzentration bei enzymatischen Prozessen. Biochem. Z. 1909, 21, 131-304.

(2) Cremer, M. Über die Ursache der elektromotorischen Eigenschaften der Gewebe, zugleich ein Beitrag zur Lehre von den polyphasischen Elektrolytketten. Z. Biol. 1906, 47, 562-608.

(3) Haber, F.; Hlemensiewicz, Z. Über elektrische Phasengrenzekräfte. Z. Phys. Chem. 1909, 67, 385.

(4) Scholz, F. From the Leiden jar to the discovery of the glass electrode by Max Cremer. J. Solid State Electrochem. 2011, 15, 5-14.

(5) Belyustin, A. A. The centenary of glass electrode: from Max Cremer to F. G. K. Baucke. J. Solid State Electrochem. 2011, 15, 4765.

(6) Gotor, R.; Ashokkumar, P.; Hecht, M.; Keil, K.; Rurack, K. Optical $\mathrm{pH}$ Sensor Covering the Range from $\mathrm{pH}$ 0-14 Compatible with Mobile-Device Readout and Based on a Set of Rationally Designed Indicator Dyes. Anal. Chem. 2017, 89, 8437-8444.

(7) Bender, M.; Bojanowski, N. M.; Seehafer, K.; Bunz, U. H. F. Immobilized Poly(aryleneethynylene) pH Strips Discriminate Different Brands of Cola. Chem.-Eur. J. 2018, 24, 13102-13105.

(8) Weidgans, O. S. W. a. B. M., Fiber optic chemical sensors and biosensors: a view back. In Optical Chemical Sensors; Baldini, F.; Chester, A. N.; Homola, J.; Martellucci, S., Eds.; Springer, 2004; pp $17-46$.

(9) Wencel, D.; Abel, T.; McDonagh, C. Optical chemical pH sensors. Anal. Chem. 2014, 86, 15-29.

(10) Lin, J. Recent development and applications of optical and fiber-optic pH sensors. TrAC, Trends Anal. Chem. 2000, 19, 541-552.

(11) Wolfbeis, O. S. Editorial: Probes, Sensors, and Labels: Why is Real Progress Slow? Angew. Chem., Int. Ed. 2013, 52, 9864-9865.

(12) Card, C.; Clark, K.; Furey, J. Adoption of Single-Use Sensors for BioProcess Operations. BioProcess Int. 2011, 9, 36-42.

(13) Weichert, H.; Lüders, J.; Becker, M.; Adams, T.; Weyand, J. Integrated Optical Single-Use Sensors: Moving Toward a True SingleUse Factory for Biologics and Vaccine Production. BioProcess Int. 2014, 12, 20-24.

(14) Janzen, N. H.; Schmidt, M.; Krause, C.; Weuster-Botz, D. Evaluation of fluorimetric $\mathrm{pH}$ sensors for bioprocess monitoring at low pH. Bioprocess Biosyst. Eng. 2015, 38, 1685-1692.

(15) Diehl, B. H.; La Pack, M. A.; Wang, T. Y.; Kottmeier, R. E.; Kaneshiro, S. M.; Brandenstein, M. C.; Zhang, Y. C.; Chiu, Y. C.; Yoon, S.; Saucedo, V. M. A Biopharmaceutical Industry Perspective on Single-Use Sensors for Biological Process Applications. BioPharm Int. 2015, 28, 28-31.

(16) Frankær, C. G.; Hussain, K. J.; Rosenberg, M.; Jensen, A.; Laursen, B. W.; Sørensen, T. J. A Biocompatible Microporous Organically Modified Silicate Material with Rapid Internal Diffusion of Protons. ACS Sens. 2018, 3, 692.

(17) Frankær, C. G.; Hussain, K. J.; Dörge, T. C.; Sørensen, T. J. Optical Chemical Sensor Using Intensity Ratiometric Fluorescence Signals for Fast and Reliable pH Determination. ACS Sens. 2019, 4, $26-31$.

(18) Irving, H. M.; Zettler, H.; Baudin, G.; Preiser, H.; Guilbault, G. G.; Menis, O.; Rice, N. M.; Robertson, A. J. B.; Docherty, A. C.; Fischer, W.; Kaiser, H.; Kirkbright, G. F.; Samuelson, O.; Svehla, G. G.; Tölg, G.; West, T. S.; Tawfik, H. A. Recommendations for Nomenclature of Ion-Selective Electrodes. Pure Appl. Chem. 1976, 48, 127-132.

(19) Lindner, E.; Tóth, K.; Pungor, E. Definition and Determination of Response-Time of Ion-Selective Electrodes. Pure Appl. Chem. 1986, $58,469-479$.

(20) Buck, R. P.; Lindner, E. Recomendations for nomenclature of ion-selective electrodes. Pure Appl. Chem. 1994, 66, 2527-2536.

(21) Sydenham, P. H., Static and Dynamic Characteristics of Instrumentation. In The Measurement Instrumentation and Sensors Handbook, Webster, J. G., Ed.; CRC Press, 1998.

(22) Kalantar-zadeh, K., Sensors An Introductory Course; Springer, 2013. 
(23) Frankær, C. G.; Sørensen, T. J. A Unified Approach for Investigating Chemosensor Properties - Dynamic Characteristics. Analyst 2019, 144, 2208.

(24) Maccà, C. Response time of ion-selective electrodes. Anal. Chim. Acta 2004, 512, 183-190.

(25) Morf, W. E.; Lindner, E.; Simon, W. Theoretical Treatment of Dynamic-Response of Ion-Selective Membrane Electrodes. Anal. Chem. 1975, 47, 1596-1601.

(26) Laursen, B. W.; Krebs, F. C. Synthesis of a triazatriangulenium salt. Angew. Chem. 2000, 39, 3432-3434.

(27) Laursen, B. W.; Krebs, F. C. Synthesis, structure, and properties of azatriangulenium salts. Chem.-Eur. J. 2001, 7, 1773-1783.

(28) Frankær, C. G.; Rosenberg, M.; Santella, M.; Hussain, K. J.; Laursen, B. W.; Sørensen, T. J. Tuning the $\mathrm{pKa}$ of a $\mathrm{pH}$ Responsive Fluorophore and the Conse-quences for Calibration of Optical Sensors based on a Single Fluorophore but Multiple Receptors. ACS Sens. 2019, 4, 764.

(29) Rosenberg, M.; Laursen, B. W.; Frankær, C. G.; Sørensen, T. J. A Fluorescence Intensity Ratiometric Fiber Optics-Based Chemical Sensor for Monitoring pH. Adv. Mater. Technol. 2018, 3, 1800205.

(30) Sørensen, T. J.; Rosenberg, M.; Frankær, C. G.; Laursen, B. W. An Optical pH Sensor Based on Diazaoxatriangulenium and Isopropyl-Bridged Diazatriangulenium Covalently Bound in a Composite Sol-Gel. Adv. Mater. Technol. 2018, 4, 1800561.

(31) Wolfbeis, O. S. Fiber-Optic Chemical Sensors and Biosensors. Anal. Chem. 2008, 80, 4269-4283.

(32) Fleet, B.; Ryan, T. H.; Brand, M. J. D. Investigation of Factors Affecting Response-Time of a Calcium Selective Liquid Membrane Electrode. Anal. Chem. 1974, 46, 12-15.

(33) Karlberg, B. Ion-Exchange Properties of Gel Layer of Some Hydrogen-Ion-Selective Glass Electrodes. J. Electroanal. Chem. 1973, 45, 127-139.

(34) Tóth, K.; Stulík, K.; Kutner, W.; Fehér, Z.; Lindner, E. Electrochemical detection in liquid flow analytical techniques: Characterization and classification - (IUPAC Technical Report). Pure Appl. Chem. 2004, 76, 1119-1138.

(35) Lindner, E.; Toth, K.; Pungor, E. Response-Time Curves of Ion-Selective Electrodes. Anal. Chem. 1976, 48, 1071-1078.

(36) Tóth, K.; Gavallér, I.; Pungor, E. Transient Phenomena of IonSelective Membrane Electrodes. Anal. Chim. Acta 1971, 57, 131-135.

(37) Rovati, L.; Fabbri, P.; Ferrari, L.; Pilati, F. Construction and evaluation of a disposable $\mathrm{pH}$ sensor based on a large core plastic optical fiber. Rev. Sci. Instrum. 2011, 82, 023106.

(38) Kosch, U.; Klimant, I.; Werner, T.; Wolfbeis, O. S. Strategies to design $\mathrm{pH}$ optodes with luminescence decay times in the microsecond time regime. Anal. Chem. 1998, 70, 3892-3897.

(39) Nivens, D.; Schiza, M. V.; Angel, S. M. Multilayer sol-gel membranes for optical sensing applications: single layer $\mathrm{pH}$ and dual layer $\mathrm{CO} 2$ and NH3 sensors. Talanta 2002, 58, 543-550.

(40) Wang, E.; Chow, K.-F.; Kwan, V.; Chin, T.; Wong, C.; Bocarsly, A. Fast and long term optical sensors for $\mathrm{pH}$ based on sol-gels. Anal. Chim. Acta 2003, 495, 45-50.

(41) Lee, S. T.; Gin, J.; Nampoori, V. P. N.; Vallabhan, C. P. G.; Unnikrishnan, N. V.; Radhakrishnan, P. A sensitive fibre optic $\mathrm{pH}$ sensor using multiple sol-gel coatings. J. Opt. A: Pure Appl. Opt. 2001, $3,355-359$.

(42) Rayss, J.; Sudolski, G. Ion adsorption in the porous sol-gel silica layer in the fibre optic pH sensor. Sens. Actuators, B 2002, 87, 397405.

(43) Sánchez-Barragán, I.; Costa-Fernández, J. M.; Sanz-Medel, A.; Valledor, M.; Ferrero, F. J.; Campo, J. C. A ratiometric approach for $\mathrm{pH}$ optosensing with a single fluorophore indicator. Anal. Chim. Acta 2006, 562, 197-203.

(44) Kocincova, A. S.; Borisov, S. M.; Krause, C.; Wolfbeis, O. S. Fiber-optic microsensors for simultaneous sensing of oxygen and $\mathrm{pH}$, and of oxygen and temperature. Anal. Chem. 2007, 79, 8486-8493.

(45) Han, C.; Yao, L.; Xu, D.; Xie, X. C.; Zhang, C. S. Highresolution Imaging of $\mathrm{pH}$ in Alkaline Sediments and Water Based on a
New Rapid Response Fluorescent Planar Optode. Sci. Rep. 2016, 6, 26417.

(46) Gonçalves, H. M. R.; Maule, C. D.; Jorge, P. A. S.; Esteves da Silva, J. C. G. Fiber optic lifetime $\mathrm{pH}$ sensing based on ruthenium(II) complexes with dicarboxybipyridine. Anal. Chim. Acta 2008, 626, 6270.

(47) Wencel, D.; MacCraith, B. D.; McDonagh, C. High performance optical ratiometric sol-gel-based $\mathrm{pH}$ sensor. Sens. Actuators, B 2009, 139, 208-213.

(48) Wencel, D.; Barczak, M.; Borowski, P.; McDonagh, C. The development and characterisation of novel hybrid sol-gel-derived films for optical pH sensing. J. Mater. Chem. 2012, 22, 11720.

(49) Jurmanović, S.; Kordić, Š.; Steinberg, M. D.; Steinberg, I. M. Organically modified silicate thin films doped with colourimetric $\mathrm{pH}$ indicators methyl red and bromocresol green as $\mathrm{pH}$ responsive sol-gel hybrid materials. Thin Solid Films 2010, 518, 2234-2240.

(50) Lobnik, A.; Oehme, I.; Murkovic, I.; Wolfbeis, O. S. pH optical sensors based on sol-gels: Chemical doping versus covalent immobilization. Anal. Chim. Acta 1998, 367, 159-165.

(51) Cajlakovic, M.; Lobnik, A.; Werner, T. Stability of new optical $\mathrm{pH}$ sensing material based on cross-linked poly(vinyl alcohol) copolymer. Anal. Chim. Acta 2002, 455, 207-213.

(52) Lindner, E.; Toth, K.; Pungor, E.; Berube, T. R.; Buck, R. P. Switched Wall Jet for Dynamic-Response Measurements. Anal. Chem. 1987, 59, 2213-2216.

(53) Rangarajan, R.; Rechnitz, G. A. Dynamic-Response of IonSelective Membrane Electrodes. Anal. Chem. 1975, 47, 324-326.

(54) Bakker, E.; Bühlmann, P.; Pretsch, E. Carrier-based ionselective electrodes and bulk optodes. 1. General characteristics. Chem. Rev. 1997, 97, 3083-3132. 